\title{
Improving of electrical channels for magnetotelluric sounding instrumentation
}

\author{
A. M. Prystai and V. O. Pronenko \\ Lviv Centre of Institute for Space Research, Lviv, Ukraine \\ Correspondence to: V. O. Pronenko (pron@isr.lviv.ua)
}

Received: 26 January 2015 - Published in Geosci. Instrum. Method. Data Syst. Discuss.: 2 April 2015

Revised: 2 July 2015 - Accepted: 16 July 2015 - Published: 30 July 2015

\begin{abstract}
The study of the deep structure of the Earth's crust is of great interest for both applied (e.g. mineral exploration) and scientific research. For this the electromagnetic (EM) studies which enable one to construct the distribution of electrical conductivity in the Earth's crust are of great use. The most common method of EM exploration is magnetotelluric sounding (MT). This passive method of research uses a wide range of natural geomagnetic variations as a powerful source of electromagnetic induction in the Earth, producing telluric current variations there. It includes the measurements of variations of natural electric and magnetic fields in orthogonal directions at the surface of the Earth. By this, the measurements of electric fields are much more complicated metrological processes, and, namely, they limit the precision of MT prospecting. This is especially complicated at deep sounding when measurements of long periods are of interest. The increase in the accuracy of the electric field measurement can significantly improve the quality of MT data. Because of this, the development of a new version of an instrument for the measurements of electric fields at MT - both electric field sensors and the electrometer - with higher levels relative to the known instrument parameter level - was initiated. The paper deals with the peculiarities of this development and the results of experimental tests of the new sensors and electrometers included as a unit in the long-period magnetotelluric station LEMI-420 are given.
\end{abstract}

\section{Introduction}

The study of the deep structure of the Earth's crust is of great interest for both applied (e.g. mineral exploration) and scientific research. The most common method of EM exploration is the magnetotelluric sounding (MT) method proposed by Tikhonov (1950) and Cagniard (1953) in the 50s of last century. This is a passive method of research, which uses a wide range of natural geomagnetic variations as a powerful source of electromagnetic induction in the Earth. The MT technique includes the measurements of variations of natural electric and magnetic fields in orthogonal directions at the surface of the Earth. Then the conductivity structure of the Earth's crust is determined by the obtained data processing. As a result the geoelectric cross section for the depths from several tens of metres to several hundred kilometres is constructed (Simpson and Bahr, 2005).

Like other methods, MT has its limitations. Particularly, the 3-D model analysis which is built on the basis of magnetotelluric data shows that the distribution of electrical conductivity in the deep or subsurface structures which contain conducting inclusions makes it possible to select the faults based on the MT data only in cases of the fault's great length. Furthermore, the magnetotelluric data interpretation is greatly complicated by 3-D subsurface heterogeneity. Fault zones with high electrical conductivity cause vertical redistribution of telluric currents, which in turn leads to an increase in the MT field response from the conductive zones in the Earth's crust which makes the interpretation difficult.

It is known that the measurement of the electric field is the biggest problem during MT. At the present stage of instrumentation technique development it is possible practically to reduce the influence of the accuracy of magnetic measurements on MT results to a negligible level. At the same time the electrical measurements, in particular for deep research when the measurements are required for a long time, are a serious methodological and hardware problem (Chave and Jones, 2012). First of all, this is due to quite small val- 


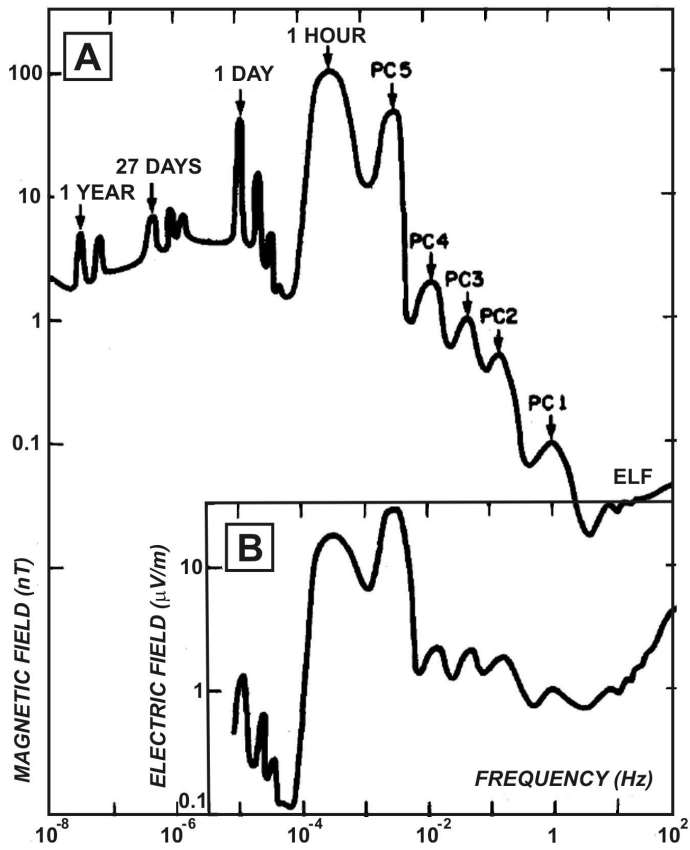

Figure 1. Natural variations of the electric and magnetic fields (from Serson, 1973).

ues of the measured variations of the electric field compared to the so-called contact potential arising at the interface of the contact of the electrode with the environment. Figure 1 shows the evaluation of the level of natural variations of the electric and magnetic fields, taken from Serson (1973). Because of the complex electrochemical reactions occurring at the electrode surface, the magnitude of the contact potential, and especially its instability, they both essentially depend on a number of physical and chemical processes in the environment.

The first method to reduce the influence of the contact potential difference instability, that is, increasing the signalnoise ratio in electrical measurements, is to increase the distance between the measuring electrodes (length of electrical lines). This solution gave a positive result under deep MT which allowed estimates of conductivity up to the Earth's mantle (Egbert and Booker, 1992; Semenov et al., 2008). But, it is not always applicable, especially when working in populated or mountainous areas where you cannot expand the long lines for the necessary long time. Another approach is to improve the quality of the measuring electrodes and electrical channels of MT stations by reducing the level of their own noise, increasing sensitivity and temporal stability. This paper is dedicated to this second approach implementation.
Table 1. Mean parameters of the electrodes immersed in wet soil

\begin{tabular}{lll}
\hline $\begin{array}{l}\text { Electrode } \\
\text { type }\end{array}$ & $\begin{array}{l}\text { Difference } \\
\text { of potentials }\end{array}$ & Resistance \\
\hline GMC & $0.86 \mathrm{mV}$ & $30.0 \mathrm{k} \Omega$ \\
Phoenix & $1.72 \mathrm{mV}$ & $1.9 \mathrm{k} \Omega$ \\
GISCO & $0.88 \mathrm{mV}$ & $1.3 \mathrm{k} \Omega$ \\
BGP & $3.30 \mathrm{mV}$ & $1.04 \mathrm{k} \Omega$ \\
LEMI & $0.06 \mathrm{mV}$ (selected pair) & $0.5 \mathrm{k} \Omega$ \\
\hline
\end{tabular}

\section{Analysis, design and implementation of an electrical measurement channel}

For the measurements of the electric field in geophysics, the so-called "non-polarized" electrodes are used. By this it is assumed that these electrodes do not chemically interact with the environment and provide low drift during long-run measurements of the electric field, which is not true. In reality, between the electrode surface and the environment in which the electrode is immersed, there is always electrochemical interaction creating the so-called polarization potential of the electrode. Measuring electric fields as the potential difference between two electrodes, we always have at the electrode pair output the voltage equal to the sum of the useful signal proportional to the electric field value in the environment and difference of such polarization potentials. By this the second term in practice is much greater than the useful signal. There are many works devoted to the investigation of the electrochemical interaction of the electrode with the surrounding conducting medium and to the methods to decrease the polarization potentials (e.g. Frumkin et al., 1952; Conway, 1965; Yu and Ji, 1993). As an issue of their finding, we may state that in order to minimize the polarization effect, the electrodes have to be manufactured using the metal immersed in its salt, and then the salt has to be in contact with the ground. The most common in geophysical practice are the electrodes from the following manufacturers: GMC ( $\mathrm{Ag}-\mathrm{AgCl})$, Phoenix Geophysics ( $\mathrm{Pb}-\mathrm{PbCl})$, GISCO $\left(\mathrm{Cu}-\mathrm{CuSO}_{4}\right)$ and $\mathrm{BGP}(\mathrm{Pb}-\mathrm{PbCl})$, and, recently, LEMI $(\mathrm{Cu}-$ $\left.\mathrm{CuSO}_{4}\right)$. For these electrodes the magnitude of the contact potential difference when immersed in a conductive medium that models the wet soil was determined experimentally (Table 1). But, as was stated above, for MT the most important parameter is not the contact potential difference value; this difference changes with time and temperature. This quantity determines the quality of the electrodes, and the accuracy and interpretation of measurements depend on it. However, this parameter was never given in the technical documentation for the electrodes; the only published data were found in Petiau (2000). As described here, in a lead electrode and its salt $(\mathrm{Pb}-\mathrm{PbCl})$, temporal drift is about $1 \mathrm{mV} \mathrm{month}^{-1}$, which requires, when viewing Fig. 1 for a reference, an electric line length of at least $\sim 1000 \mathrm{~m}$ if we wish to have the same order 


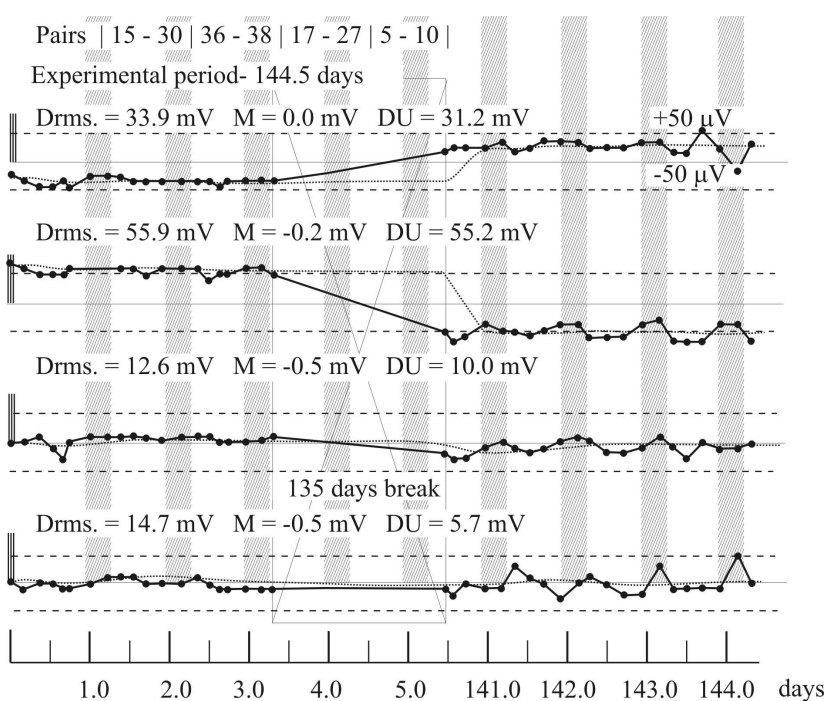

Figure 2. Long-term drift of the potential difference of selected pairs of electrodes. Here: Drms - root mean square error; $M$ - zero line shift. DU is averaged for 1-day dispersion.

of magnitude of the measured daily variations of the electric field, which is difficult to realize in practice.

Recently new regulations in Europe require the elimination of lead and its composites from use. This fostered the resumption of the study of other possible materials and structures of the electrodes. As a starting point, the electrode on the basis of copper and copper sulfate $\left(\mathrm{Cu}-\mathrm{CuSO}_{4}\right)$ was adopted. The shortcomings of such a construction of a nonpolarized electrode based on the combination of $\mathrm{Cu}-\mathrm{CuSO}_{4}$ were studied (Korepanov and Svenson, 2007) and as a result a new improved design of a non-polarized LEMI-701 electrode was proposed (LCISR, 2014).

Geophysical electrodes LEMI-701, except for environmental safety ( $\mathrm{Cu}$ salt works as fertilizer), possess significant advantages as compared with lead electrodes. For comparison, the measured noise level of randomly selected pairs of electrodes LEMI-701 is $\sim 20 \mathrm{nV}$ at $1 \mathrm{~Hz}$ vs. $0.4 \mathrm{mV}$ for $\mathrm{Pb}-\mathrm{PbCl}$ (Petiau, 2000). For matched pairs after calibration and a specially designed selection procedure, average drift over 4 months was $50-60 \mu \mathrm{V}$ for LEMI-701 (Korepanov and Svenson, 2007), see Fig. 2, against $1 \mathrm{mV} \mathrm{month}^{-1}$ for $\mathrm{Pb}-$ $\mathrm{PbCl}$ electrodes (Petiau, 2000). With such a level of the drift, the requirements for the electrode line length become much more practical: referring again to Fig. 1, we may conclude that the baseline about $50-60 \mathrm{~m}$ is already admissible for getting the signal-noise ratio for diurnal variations close to unity.

Apart from the electrodes, the parameters of the used measuring equipment - an electrometer - also play an important role in improving the quality of the electric field measurement. A number of specific requirements should be taken into account in such an instrument design because it must

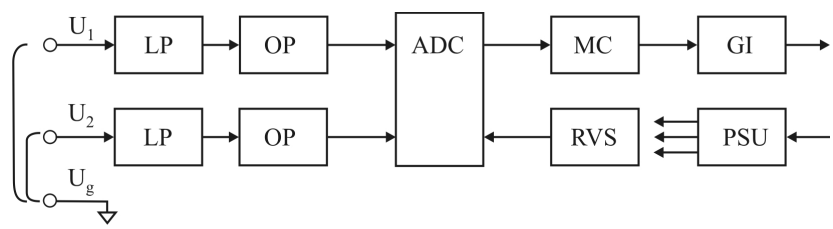

Figure 3. Functional diagram of the LEMI-420 channel for electrical measurements. Here: $U_{1}, U_{2}, U_{g}$ - input voltage; LP - circuit which protects against lightning-induced large voltage; $\mathrm{OP}$ - operational amplifier; ADC - analogue/digital converter; RVS - reference voltage source; $\mathrm{MC}$ - microcontroller; GI - galvanic isolation; PSU - power supply unit.

measure signals with periods ranging from fractions of seconds to about $100000 \mathrm{~s}$ with minimal error in field conditions at sufficiently large environmental temperature variations. In this the very important requirement is the absence of the currents in the input circuits - if they are flowing through the electrodes and the ground, they are infringing the electrochemical equilibrium at the electrode-environment contact surface. Simultaneous demands to transmit practically DC signals and input current minimization greatly complicate the task of electrometer development. To solve this task, the sophisticated technology of input circuit galvanic isolation while simultaneously meeting the requirements of high input resistance is used. For this, as Fig. 1 shows, the sensitivity threshold of the electrometer should not exceed $0.1 \mu \mathrm{V} \mathrm{m}^{-1}$ in order to provide sufficient accuracy. Typically the length of the measuring line is selected in the range of 50 to $200 \mathrm{~m}$, which gives a minimum input signal level of about $0.05 \mathrm{mV}$, while soil resistance can reach up to several hundred kohm (for frozen ground). Depending on the soil resistance and the electrode quality, the initial level of the input signal can reach hundreds of $\mathrm{mV}$; we will reserve a maximum value equal to $1 \mathrm{~V}$. Also, as much as possible, low power consumption is an essential requirement.

Last but not least is the necessity to have the protection of input stages from nearby lightning occurring often during the field season - the long electric line presents an excellent antenna to create large voltages at its output at nearby lightning discharge.

All these requirements were taken into account at the development of an electrical channel of a new MT station LEMI-420 (http://www.isr.lviv.ua). The functional diagram of the LEMI-420 electrical channel is presented in Fig. 3. Such an electrometer has an extended measurement range of the input signal up to $\pm 2450 \mathrm{mV}$, its sensitivity threshold is reduced to $0.08 \mu \mathrm{V}$, and the power consumption is less than $110 \mathrm{~mW}$ for four channels. The frequency response of the electrometer may be selected from the pre-programmed versions or be controlled by the user. This paper presents the electrometer with the following parameters: gain is equal unity; and digitizing frequency is equal to $225 \mathrm{~Hz}$ (these samples are averaged to $1 \mathrm{~Hz}$ ). There are also the following ad- 
Table 2. Comparative table of main MT station parameters of leading manufacturers.

\begin{tabular}{|c|c|c|c|c|}
\hline MTS/parameter & LEMI-420 & NIMS & ADU-07e & KMS-820 \\
\hline Channel number & 7 & 5 & 10 & 6 \\
\hline $\begin{array}{l}\text { Magnetic field } \\
\text { meter type }\end{array}$ & FGM & FGM & $\begin{array}{l}\text { FGM (also } \\
\text { IM) }\end{array}$ & $\begin{array}{l}\text { FGM (also } \\
\text { IM) }\end{array}$ \\
\hline Frequency range & $\mathrm{DC}-0.5 \mathrm{~Hz}$ & $\begin{array}{l}3 \times 10^{-5} \\
-0.5 \mathrm{~Hz}\end{array}$ & $\begin{array}{l}2 \times 10^{-5} \\
-1000 \mathrm{~Hz}\end{array}$ & $\begin{array}{l}\text { DC } \\
-50 \mathrm{kHz}\end{array}$ \\
\hline $\begin{array}{l}\text { Magnetometer } \\
\text { noise at } 1 \mathrm{~Hz}\end{array}$ & $7 \mathrm{pT} \mathrm{Hz}^{-1 / 2}$ & $10 \mathrm{pT} \mathrm{Hz}^{-1 / 2}$ & $0 \mathrm{pT} \mathrm{Hz}^{-1 / 2}$ & $10 \mathrm{pT} \mathrm{Hz}^{-1 / 2}$ \\
\hline $\begin{array}{l}\text { Electrometer } \\
\text { measuring range } \\
\text { (amplification) }\end{array}$ & $\pm 2450 \mathrm{mV}(1)$ & $\begin{array}{l} \pm 250 \mathrm{mV}(10) \\
\pm 25(100) \mathrm{mV}\end{array}$ & - & $\begin{array}{l} \pm 2.5 \mathrm{~V} \\
\text { (up to } \\
2500 \text { ) }\end{array}$ \\
\hline ADC digits, bit & 32 & 24 & 24 & 24 \\
\hline $\begin{array}{l}\text { Electrometer } \\
\text { noise at } 1 \mathrm{~Hz} \\
\text { (amplification) }\end{array}$ & $<0.08 \mu \mathrm{V} \mathrm{Hz}^{-1 / 2}(1)$ & $<0.11 \mu \mathrm{V} \mathrm{Hz}^{-1 / 2}(100)$ & No data & $<0.08 \mu \mathrm{V} \mathrm{Hz}^{-1 / 2}(40)$ \\
\hline Sampling rate & $1 \mathrm{~Hz}$ & $8 \mathrm{~Hz}$ & $4096 \mathrm{~Hz}$ & $100 \mathrm{kHz}$ \\
\hline Memory volume & $32 \mathrm{~GB}$ & $4 \mathrm{~GB}$ & $32 \mathrm{~GB}$ & $32 \mathrm{~GB}$ \\
\hline Supply voltage & $5-28 \mathrm{~V}$ & $+12 \mathrm{~V}$ & $+12 \mathrm{~V}$ & $7.5-32 \mathrm{~V}$ \\
\hline
\end{tabular}

vantages of this design: the possibility to use a low-pass digital filter with the desired frequency band and suppression factor, and to change the channel gain with a corresponding decrease in the input voltage operating range. Another advantage is the compensator absence: having the amplification factor only unity, this allows covering of all really possible initial shifts of input voltage, and this also helps to reduce the own noise level at low frequencies. Reduction of power consumption is achieved by using both galvanic separation in the digital part of the circuit and galvanic isolation in the power supply. In this case the electrode potentials are measured on relatively galvanically isolated ground.

Table 2 shows the comparative parameters of the MT stations of the leading producers at the world market. We selected MT stations with a flux-gate magnetometer (FGM) only because we concentrate our study on the instruments for a long-period survey.

\section{Field test results}

To confirm the advantages of MT station LEMI-420 electric channels, the comparative field tests with a previous version of MT station LEMI-417 were made at the site near the village of Kobaky, Ivano-Frankivsk region.

Special attention was paid to the electrode installation, which is necessary for long-term measurements. First, the proper selection of places where the electrodes have to be buried was made: as far as possible, similar places for the ar-

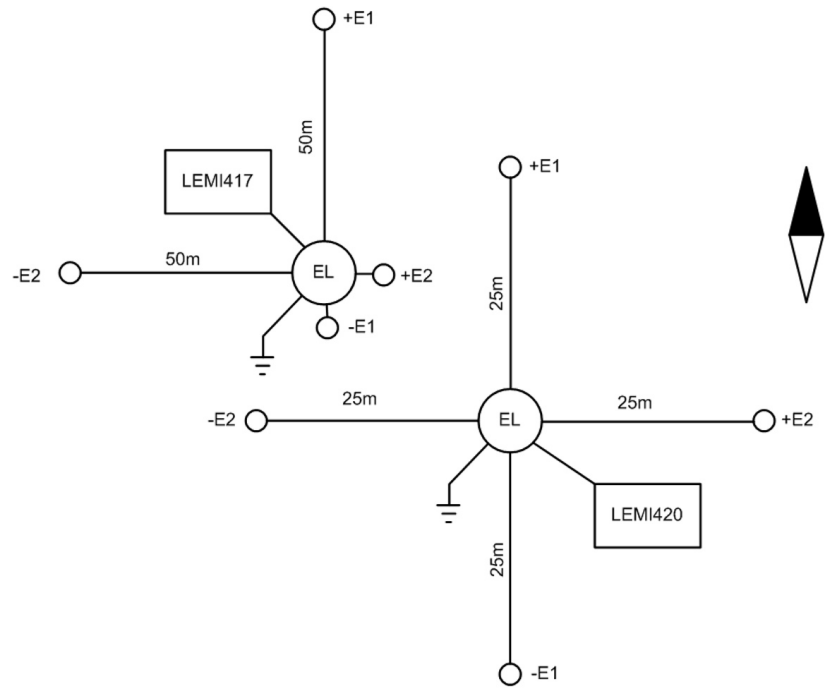

Figure 4. Electric channel setting.

rangement of two electrodes comprising one measuring line were found using the following principal requirements: the same soil composition and orographic features (i.e. hill-hill or valley-valley, under the tree-under the tree, etc.) and especially moisture conditions. The setting of the LEMI-420 and LEMI-417 electrical lines is presented in Fig. 4.

To avoid daily thermal variations, the hole depths for electrode installation were made about $70-80 \mathrm{~cm}$. There are two 


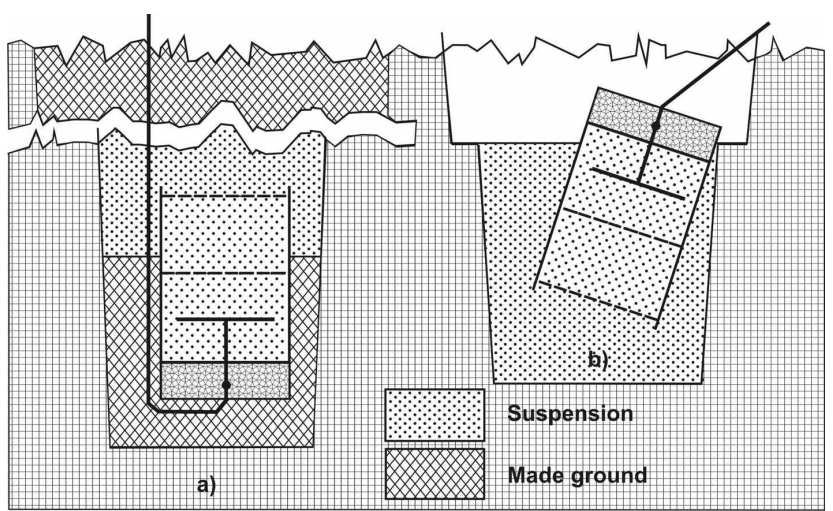

Figure 5. Electrode installation in operation position: (a) long-term and (b) short-term.

ways to install the electrodes at field works: "bottom up" for long-term installations more than 1 week (see Fig. 5a), and in a tilted position for a short time (see Fig. 5b). When preparing installation, the suspension has to be prepared first: it is made by mixing the made ground taken from the installation place and $10 \% \mathrm{CuSO}_{4}$ solution in enough quantity to cover the electrode.

The advantages of bottom-up installation are, first, that the surrounding soil in this position with time is permanently in good contact with the sensitive part of the electrode - porous partition (opposite to the cable part in Fig. 5) - and in a tilted position, the soil, though it makes better contact with the partition than in a direct position, may come off this part with time. For long-term installation it is recommended, after burying the electrode in the ground, to pour $10 \% \mathrm{CuSO}_{4}$ solution on this place. Taking into account that $\mathrm{Cu}$ salt works as fertilizer, this will not spoil the environment, in contrast to the salt solution used for Cl-based electrodes as above. For sandy soil, a special arrangement may be recommended if long-term installation is planned: the electrode is installed again in a bottom-up position, not directly in the ground, but in a plastic bucket open from above. This will save poured liquid and maintain lower resistance of the soil.

In our experiment, because the soil was clayish and the measurement time was rather short, we used the installation shown in Fig. 5b. To verify the installation reliability, the electrode pair resistance was checked. In this it is very important, as said above, to avoid creating currents flowing through the electrodes. For this a voltmeter with input resistance $\geq 10 \mathrm{M} \Omega$ and $10 \mu \mathrm{V}$ resolution and a reference resistor have to be used. First, the voltmeter has to be coupled to the output wires of electrodes and the voltage $U_{1}$ measured (see Fig. 6). Then the reference resistor $R=3 \mathrm{k} \Omega$ is connected for a short time to both electrode outputs and the voltage $U_{2}$ is measured. The value of the transient resistance $R_{l}$ of electrodes to ground and soil was calculated as

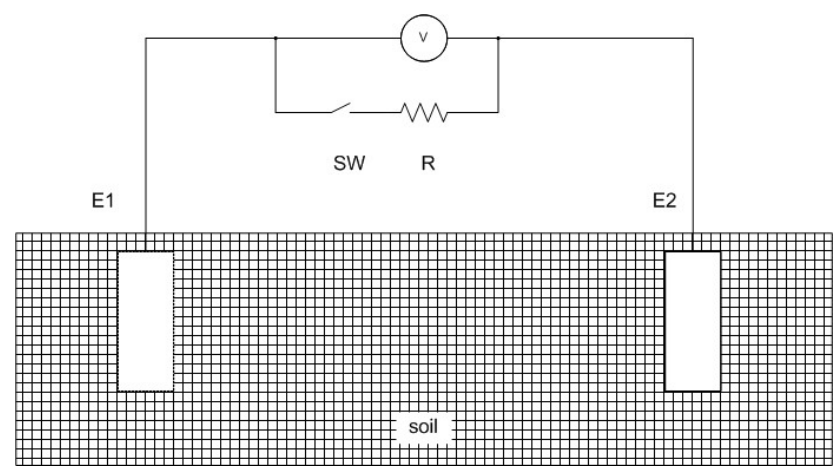

Figure 6. Electrode resistance measurement diagram.

$R_{l}=\frac{R\left(U_{1}-U_{2}\right)}{U_{2}}$,

with $U_{1}=40 \mathrm{mV}, U_{2}=10 \mathrm{mV}$, and $R=3 \mathrm{k} \Omega$; we get $R_{l}=9 \mathrm{k} \Omega$, which confirmed rather moderate soil resistance. Use of this method of resistance measurement may not always give good results. It does not work properly in areas with a high electrical noise level, such as large cities, places near electric power lines, and routes of electric trains. On the other hand, it is not possible to obtain high-quality datacarrying measurements in such noisy places; so, the success of this test may also be an indicator of a clean enough electromagnetic environment.

The resulting noise spectra of electric channels for various modifications of stations are shown in Fig. 7. Here curves 1 and 2 reflect measured natural signal spectra along the $X$ and $Y$ components correspondingly; lower curves are noise levels measured with short-circuited inputs for former versions of MT stations (curves 3 and 4) and for the LEMI-420 one (curve 5) divided by the length of the electrical lines used in curves 1 and 2 . As is seen, the instrumental noise of the stations under test is about the same at longer periods, but LEMI-420 has a considerably lower noise level at shorter periods, which is very important: if we refer to Fig. 1 again, we may see that just in this range the signal level is much lower than for longer periods.

\section{Conclusions}

Development of EM methods for studying the Earth's interior requires the improvement of resolution and precision of the measuring instruments in order to get higher quality of the interpretation of field data. It is stated that the main limiting factor in improving the MT results is low accuracy of measurement of electrical fields. So, raising the quality of electric channels of MT stations, both sensors and electronic units, is the way to overcome this shortcoming. A new design of non-polarizing electrodes with a lower noise level and higher stability in comparison with the existing analogues is suggested. In the result of the research, the upgraded version 


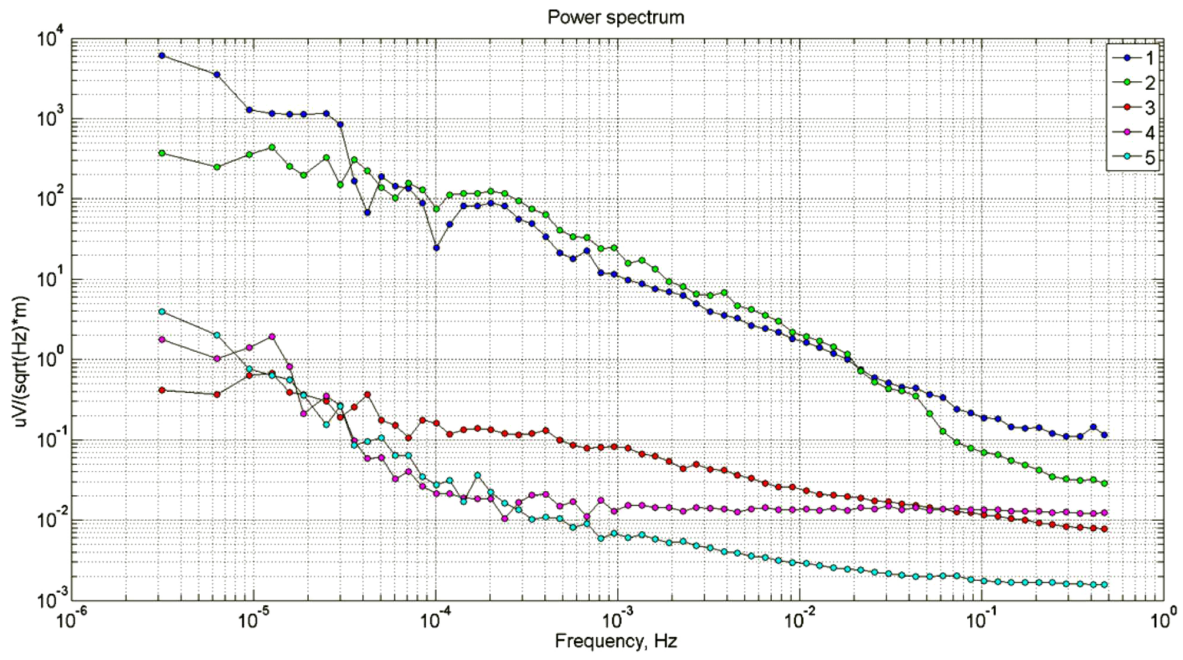

Figure 7. Power spectra of natural signals and instrumental noise levels. Here curves 1 and 2 are measured natural signal spectra along the $X$ and $Y$ components correspondingly. Curves 3 and 4 - noise levels measured with short-circuited inputs for former versions of MT stations and (curve 5) for station LEMI-420, both divided by the same inter-electrode distance as for curves 1 and 2.

of the electric field meter was developed and tested. This newly created electrometer is included in the long-period magnetotelluric station LEMI-420. To confirm the benefits of MT station LEMI-420, its field tests were carried out and a comparison of the instrumental noise level power spectra confirmed its advantage.

Acknowledgements. The authors are grateful to V. Tregubenko for the assistance in field tests and the results discussion.

Edited by: L. Vazquez

\section{References}

Cagniard, L.: Basic theory of the magneto-telluric method of geophysical prospecting, Geophysics, 18, 605-635, 1953.

Chave, A. D. and Jones, A. G.: The Magnetotelluric Method, in: Theory and Practice, Cambridge University Press, 2012.

Conway, B.: Theory and Principles of electrode processes, Ronald Press, New York, 1965.

Egbert, G. D. and Booker, J. R.: Very long period magnetotellurics at Tucson Observatory: Implications for mantle conductivity, J. Geophys. Res., 97, 15113-15128, doi:10.1029/92JB01252, 1992.
Frumkin, A., Bagotsky, V., Iofa, Z., and Kabanov, V.: Kinetics of electrode processes, MGU, Moscow, 1952.

Korepanov, V. and Svenson, A.: High-precision non-polarized electrodes for geophysical prospecting, Naukova Dumka, Kiev, 2007.

LCISR: httP://www.isr.lviv.ua (last access: 15 July 2015), 2014.

Petiau, G.: Second generation of lead-lead chloride electrodes for geophysical applications, Pure Appl. Geophys., 157, 351-382, 2000.

Semenov, V., Pek, J., Ádám, A., Jóźwiak, W., Ladanivskyy, B., Logvinov, I. M., Pushkarev, P., Vozar, J., and Experimental Team of CEMES Project: Electrical Structure of the Upper Mantle Beneath Central Europe: Results of the CEMES Project, Acta Geophysica, 56, 957-981, doi:10.2478/s11600-008-0058-2, 2008.

Serson, P.: Instrumentation for induction studies on land, Phys. Earth Planet. Inter., 7, 313-322, 1973.

Simpson, F. and Bahr, K.: Practical Magnetotellurics, Cambride University Press, 2005.

Tikhonov, A. N.: About the determination of electric characteristics of deep layers of Earth's crust, Rep. Acad. Sci. USSR, 73, 295297, 1950.

Yu, T. and Ji, G.: Electrochemical methods in soil and water research, Perg. Press, Oxford, 1993. 